\begin{tabular}{|c|l|}
\hline Title & $\begin{array}{l}\text { Molecular characterization and histochemical demonstration of sal mon olfactory marker protein in the olfactory } \\
\text { epithelium of lacustrine sockeye sal mon (Oncorhynchus nerka) }\end{array}$ \\
\hline Author(s) & Kudo, H.; Doi, Y.; Ueda, H.; Kaeriyama, M. \\
\hline Citation & $\begin{array}{l}\text { Comparative Biochemistry and Physiology. Part A, Molecular \& Integrative Physiology, 154(1), 142-150 } \\
\text { https://doi.org/L0.1016/.cbpa.2009.05.123 }\end{array}$ \\
\hline Issue Date & 2009-09 \\
\hline Doc URL & http://hdl.handle.net/2115/38841 \\
\hline Type & article(author version) \\
\hline File Information & CBP_A_ms17027_Kudo.pdf \\
\hline
\end{tabular}

Instructions for use 
CBP manuscript 17027 - Part A (Accepted Ver.)

\title{
Molecular characterization and histochemical demonstration of salmon olfactory marker protein in the olfactory epithelium of lacustrine sockeye salmon (Oncorhynchus nerka)
}

H. Kudo ${ }^{\text {a, }}$, Y. Doi ${ }^{\text {b }}$, H. Ueda ${ }^{\text {c }}$, M. Kaeriyama ${ }^{\text {a }}$

${ }^{a}$ Laboratory of Strategic Studies on Marine Bioresource Conservation and Management, Faculty of Fisheries Sciences, Hokkaido University, Hakodate 041-8611, Japan

${ }^{\mathrm{b}}$ Department of Anatomy, University of Occupational and Environmental Health, School of Medicine, Kitakyushu 807-8555, Japan

${ }^{\mathrm{c}}$ Laboratory of Aquatic Ecosystem Conservation, Field Science Center for Northern Biosphere, Hokkaido University, Sapporo 060-0809, Japan

Key words: olfactory marker protein - olfactory receptor neuron - cloning - in situ hybridization - immunocytochemistry - Pacific salmon - Teleostei

*Correspondence to: Hideaki Kudo, PhD, Laboratory of Strategic Studies on Marine Bioresource Conservation and Management, Faculty of Fisheries Sciences, Hokkaido University, Hakodate 041-8611, Japan.

Tel \&Fax: +81-138-40-5602, E-mail: hidea-k@,fish.hokudai.ac.jp

\begin{abstract}
Despite the importance of olfactory receptor neurons (ORNs) for homing migration, the expression of olfactory marker protein (OMP) is not well understood in ORNs of Pacific salmon (Genus Oncorhynchus). In this study, salmon OMP was characterized in the olfactory epithelia of lacustrine sockeye salmon (O. nerka) by molecular biological and histochemical techniques. Two cDNAs encoding salmon OMP were isolated and sequenced. These cDNAs both contained a coding region encoding 173 amino acid residues, and the molecular mass of the two proteins was calculated to be 19,581.17 and 19,387.11 Da, respectively. Both amino acid sequences showed marked homology (90\%). The protein and nucleotide sequencing demonstrates the existence of high-level homology between
\end{abstract}


salmon OMPs and those of other teleosts. By in situ hybridization using a digoxigeninlabeled salmon OMP cRNA probe, signals for salmon OMP mRNA were observed preferentially in the perinuclear regions of the ORNs. By immunohistochemistry using a specific antibody to salmon OMP, OMP-immunoreactivities were noted in the cytosol of those neurons. The present study is the first to describe cDNA cloning of OMP in salmon olfactory epithelium, and indicate that OMP is a useful molecular marker for the detection of the ORNs in Pacific salmon.

\section{Introduction}

Pacific salmon (Genus Oncorhynchus) exhibits the most representative anadromous migration between the natal stream and the sea. The homing migration of salmon to the natal stream is one of the most interesting phenomena in fish biology. It is generally accepted that salmon imprint some odorants of their natal streams on downstream migration (Stabell, 1992), and use their olfaction to identify those streams during spawning migration. Despite the importance of the olfactory system for the olfactory imprinting, the neurological and molecular biological mechanisms of these phenomena are not well understood in the salmon. Olfactory stimuli are transmitted to the brain through the olfactory receptor neurons (ORNs) in salmon as well as other vertebrates. For histological and cytological approaches, the straightforward detection of ORNs is important in salmon migration research. Previous studies demonstrated that glutathione S-transferase (GST; EC 2.5.1.18) class pi (salmon olfactory GST; soGST), as a phase II xenobiotic metabolizing enzyme, was one of the molecular markers of ORNs in the lacustrine sockeye salmon (O. nerka; Shimizu et al., 1993; Kudo et al., 1996, 1999), and in the rainbow trout (O. mykiss; Starcevic and Zielinski, 1995, 1997). In a recent study, GST activities in the olfactory epithelia of rainbow trout significantly increased in the presence of an environmentally realistic pesticide mixture (Tierney et al., 2008). These results indicated that salmon ORNs were related to both olfaction and xenobiotic metabolism in olfactory organs. It is essential to investigate more direct molecular markers of olfaction in salmon ORNs.

Olfactory marker protein (OMP) is an abundant $19 \mathrm{kDa}$ cytoplasmic protein that is almost exclusively expressed in mature, but not immature, ORNs of vertebrates (e.g., Keller and Margolis, 1975; Farbman and Margolis, 1980), and only in small numbers in other neuronal populations (Baker et al., 1989). The important role of OMP in ORN function was confirmed by generating OMP knockout mice (Mus musculus) whose electrophysiological 
responces to odorants are impaired (Buiakova et al., 1996; Ivic et al., 2000) and whose detection threshold for odors is increased 50-100 fold (Youngentob and Margolis, 1999; Youngentob et al., 2001), demonstrating a modulatory function in olfactory signal transduction. In fish, some previous studies have demonstrated this through immunohistochemical analyses and molecular cloning (Celik et al., 2002; Yoshida et al., 2002; Yasuoka et al., 1999, Ferrando et al., 2007). However, in salmonid fish, immunohistochemistry using antibodies against mammalian OMP has only been conducted in ORNs of rainbow trout (Riddle and Oakley, 1992). The biochemical and molecular biological characters of salmon OMP remain to be fully elucidared, although OMP-like substances exist in the ORNs of rainbow trout.

In this study, salmon OMP was characterized in the olfactory epithelia of lacustrine sockeye salmon by employing molecular biological and histochemical techniques, showing that OMP is a useful molecular marker for ORNs in Pacific salmon. In addition, we conducted immunohistochemical analyses of soGST and protein gene product 9.5 (PGP9.5), as broad developmental ORN marker, to compare localization with OMP and other ORN marker molecules.

\section{Materials and methods}

\subsection{Animals}

One-year-old lacustrine sockeye salmon of both sexes used in this study were reared at Toya Lake Station, Field Science Center for Northern Biosphere, Hokkaido University, in outdoor FRP tanks supplied with a continuous flow of spring water at an ambient temperature and under natural photoperiod conditions (body length [fork length] $130 \pm 1.10 \mathrm{~mm}$ and body weight $21 \pm 0.5 \mathrm{~g} ;$ mean $\pm \mathrm{SE})$. Fish were anesthetized with 2-phenoxyethanol (200 mg/l), and the olfactory rosettes, including the olfactory epithelia, were surgically isolated.

Male Wistar rats (Rattus norvegicus) aged 8 weeks and weighing $250 \pm 30 \mathrm{~g}$ (Seac Yoshitomi, Fukuoka, Japan) were provided for the present study. The care and use of animals followed 'The Guiding Principles for the Care and Use of Animals', approved by our university in accordance with the principles of the Declaration of Helsinki. Rats were deeply anesthetized with an intraperitoneal injection of $5 \mathrm{mg}$ of pentobarbital per $100 \mathrm{~g}$ body weight and perfused intracardially with physiologic saline. After perfusion, the nasal cavities, including the olfactory epithelia, were carefully dissected and removed for OMP- 
immunohistochemistry. Paraffin sections and soluble extracts were prepared according to the procedure described by Kudo et al. (2000) and Nishino et al. (2001), respectively.

\subsection{RNA preparation}

Total RNA was prepared from the olfactory epithelia of lacustrine sockeye salmon by the acid guanidium thiocyanate-phenol-chloroform extraction method (Chomczynski and Sacchi, 1987) using ISOGEN (Nippongene, Tokyo, Japan). Poly(A) ${ }^{+}$RNA was isolated by oligo(dT)-Latex beads (Oligotex-dT30<Super $>$; Takara, Otsu, Japan).

\subsection{Oligonucleotides}

Oligonucleotides used as PCR primers are shown in Table 1. The degenerate primer pair (OMPdn-F and OMPdn-R) was designed against highly conserved regions of OMP cDNA of

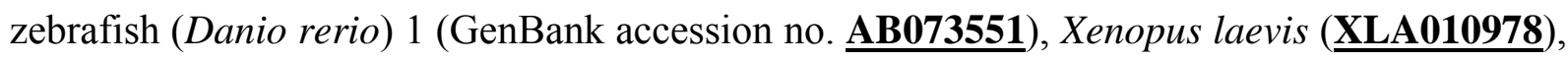

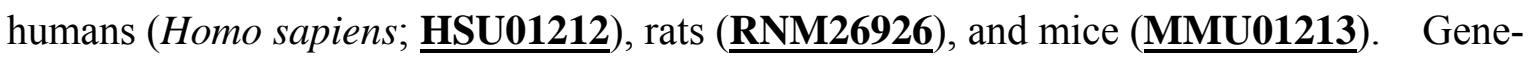
specific primers were synthesized based on our partial sequences of salmon OMP cDNA.

\subsection{Cloning of salmon OMP $c D N A$}

Described briefly as above, five hundred nanograms of poly $(\mathrm{A})^{+}$RNA from the olfactory epithelium was reverse transcribed using an oligo (dT) primer and Super Script ${ }^{\mathrm{TM}} \mathrm{II}_{\mathrm{RNaseH}} \mathrm{RN}^{-}$ Reverse Transcriptase (Gibco BRL, Rockville, MD) according to the manufacturer's instructions. PCR was performed using degenerate primers OMPdn-F and OMPdn-R) designed from a highly conserved region of known OMP sequences. The PCR conditions were: the first cycle, denaturation at $94^{\circ} \mathrm{C}$ for $3 \mathrm{~min}$, annealing at $55^{\circ} \mathrm{C}$ for $5 \mathrm{~min}$, and extension at $72^{\circ} \mathrm{C}$ for $5 \mathrm{~min} ; 35$ cycles of incubation, $30 \mathrm{sec}$ at $94^{\circ} \mathrm{C}, 30 \mathrm{sec}$ at $55^{\circ} \mathrm{C}$, and 1 min at $72^{\circ} \mathrm{C}$; and finally extension at $72^{\circ} \mathrm{C}$ for 5 min for $3^{\prime}$ A overhangs using the GeneAmp PCR System 9700 (Applied Biosystems, Foster City, CA). The amplicons were T-A ligated to pCRII-TOPO vector (TOPO TA Cloning Kit; Invitrogen, San Diego, CA) and sequenced.

Based on the sequence information of the presumptive OMP cDNA amplicon, rapid amplification of cDNA ends (RACE) procedures were performed to isolate the 5' and 3' ends of the cDNA (SMART RACE cDNA Amplification Kit; Clontech Laboratories, Mountain View, CA). In each RACE procedure, the initial PCR amplification was followed by nested amplification. Gene-specific primer sets (sp series) in combination with adaptor primers 
were used, respectively, for 5'- and 3'-RACE. RACE PCR cycling conditions were 35 cycles with $5 \mathrm{sec}$ at $94^{\circ} \mathrm{C}, 10 \mathrm{sec}$ at $70^{\circ} \mathrm{C}$ or $68^{\circ} \mathrm{C}$, and $2 \mathrm{~min}$ at $72^{\circ} \mathrm{C}$.

\subsection{DNA sequencing analysis}

The resulting plasmid DNA was alkaline-denatured and both strands were sequenced using a Dye Terminater Cycle Sequencing Kit and ABI Prism Model 3100 Auto Sequencer (Applied Biosystems, Foster City, CA). Sequence analysis and comparison were carried out using DNASIS software (Hitachi Software Engineering Co., Ltd., Tokyo, Japan). The sequences of salmon OMP1 and OMP2 were deposited in GenBank (accession numbers $\underline{\mathbf{A B 4 9 0 2 5 0}}$ and AB490251, respectively). The alignment of multiple protein sequences was performed using the ClustalW multiple sequence alignment program, and homology values (percent of amino acid sequence identity) were calculated by pair-wise alignment. A phylogenetic tree was constructed using the Neighbor-joining method (Saitou and Nei, 1987) and viewed with TreeViewX (Ver. 0.5.0). Program settings are detailed in Figure legends.

\subsection{Polyclonal antibody production}

For antigen of the salmon OMP antibody, synthetic peptide was synthesized at Genenet Co., Ltd. (Fukuoka, Japan) and coupled to bovine serum albumin (BSA). The peptide chain was designed against highly conserved regions of OMP amino acid sequences of salmon and other teleosts (Fig. 2; 92-110; SQLWTPDLTHLMTRQLLEP-C). A rabbit was injected with 150 $\mu \mathrm{g}$ BSA-conjugated synthetic peptide in Freund's complete adjuvant and boosted at 2-week intervals by the subcutaneous injection of $300 \mu \mathrm{g}$ of the antigen. The rabbit was bled one week after the fifth injection. Antiserum was purified with affinity peptide column coupling using the same peptide as above. The titer and specificity of purified antibody was tested by ELISA and western blotting analyses.

\subsection{Western blot analysis}

Soluble extracts from lacustrine sockeye salmon olfactory rosettes and rat nasal cavities containing $20 \mu \mathrm{g}$ protein, as determined by Lowry's method (Lowry et al., 1951), were heated at $100^{\circ} \mathrm{C}$ for $2 \mathrm{~min}$ in $3 \%$ sodium dodecyl sulfate (SDS) with a reduction with $10 \% 2$ mercaptoethanol. They were separated using 15\% SDS- polyacrylamide gel electrophoresis (PAGE), and the separated proteins were stained with $0.1 \%$ Coomassie brilliant blue R-250 in a mixture of $40 \%$ ethanol, $10 \%$ acetic acid, and 50\% DDW. Protein molecular weight 
markers (low MW set) were obtained from Pharmacia (Uppsala, Sweden). Proteins resolved by SDS-PAGE were transferred to a polyvinylidene difluoride membrane (Millipore, Bedford, MA) with a Semidry Trans-blot SD (Bio-Rad, South Richmond, CA). The membrane was incubated for $1 \mathrm{~h}$ with 5\% skim milk in TBS to reduce non-specific protein absorption, and allowed to react overnight with purified salmon OMP polyclonal antibody at a dilution of 1:500 in Solution 1 of Can Get Signal (Toyobo, Osaka, Japan). After rinsing with Trisbuffered saline (TBS), the membrane was incubated with horseradish-peroxidase-conjugated goat anti-rabbit IgG (Bio-Rad) at a dilution of 1:1000 in TBS for $3 \mathrm{~h}$, developed in $0.06 \%$ chloro-1-naphthol solution in TBS containing $0.01 \% \mathrm{H}_{2} \mathrm{O}_{2}$ between 3 and $5 \mathrm{~min}$, and air-dried. The specificity of the above immunoreactivities was confirmed by replacing the primary antibody with pre-immuno serum.

\subsection{Immunohistochemistry}

Serial paraffin sections of lacustrine sockeye salmon olfactory epithelia of both sexes were prepared according to the procedure described by Kudo et al. (1996). After deparaffinization and hydration, sections were blocked with $0.3 \% \mathrm{H}_{2} \mathrm{O}_{2}$ in absolute methanol for $20 \mathrm{~min}$ to remove endogenous peroxidase. After rinsing with phosphate-buffered saline (PBS), they were incubated with 10\% BSA in PBS for 15 min followed by incubation in a humid chamber with one of the following: the purified rabbit anti-salmon OMP polyclonal antibody, rabbit anti-salmon olfactory GST (soGST) polyclonal antibody (anti-N24; Shimizu et al., 1993; Kudo et al., 1999), or rabbit anti-protein gene product 9.5 (PGP9.5) polyclonal antibody (UltraClone, Cambridge, UK) at a dilution from 1:200 to 1:2000 in PBS for $16 \mathrm{~h}$ at $4^{\circ} \mathrm{C}$. After rinsing in PBS, sections were reacted using the indirect immunoperoxidase method (Histofine Simple Stain MAX-PO Kit, Nichirei, Tokyo, Japan). The specificity of the above antibody was confirmed by a preabsorption test with antigenic peptide for it. The peroxidase complex was visualized by treatment with a freshly prepared diaminobenzidine tetrahydrochloride $(0.1 \mathrm{mg} / \mathrm{mL})$ solution with $0.01 \% \mathrm{H}_{2} \mathrm{O}_{2}$ for $5 \mathrm{~min}$ at room temperature. The specificity of the above immunoreactivities was confirmed by replacing the primary antibody with pre-immuno serum.

The double immunofluorescence method was performed in order to compare the localization between OMP and GST in the same sections. Two-step immunoreactions for primary antibodies were carried out as described below because both antibodies were rabbit polyclonal antibodies. Sections were treated with $10 \%$ normal donkey serum in PBS for 30 
min, and first immunoreacted with purified rabbit anti-salmon OMP antibody at a dilution of 1:100 in PBS for $16 \mathrm{~h}$ at $4^{\circ} \mathrm{C}$. After PBS washing, sections were reacted with Alexa Fluor 488 donkey anti-rabbit IgG conjugate (Molecular Probes, Eugene, OR) at a dilution of 1:100 in PBS for $2 \mathrm{~h}$ at room temperature. All incubations were carried out in a humid and dark chamber. Sections were coverslipped with 90\% nonfluorescent glycerol containing 7.5 $\mu \mathrm{g} / \mathrm{mL}$ of 4', 6-diamino-2-phenylindole dihydrochloride (DAPI) in PBS, and digitally captured on a fluorescence microscope (Eclipse 80i, Nikon, Tokyo, Japan) equipped with a Canon EOS 5D camera (Tokyo, Japan). Decoversliped sections were treated with the antibody-removal solution ( $0.2 \mathrm{~mol} / \mathrm{L}$ glycine in DDW; $\mathrm{pH} 2.8)$ for $16 \mathrm{~h}$ at room temperature under stirring. After washing with 0.5 M Tris-HCl buffer ( $\mathrm{pH} 7.8)$, sections were checked for residual fluorescence using fluorescence microscope. Secondary immunoreaction was performed by replacing OMP antibody and Alexa Fluor 488 with rabbit anti-salmon olfactory GST antibody and Alexa Fluor 546, respectively. The captured images of both OMP- and GST-immunoreactions were superimposed based on the DAPI-counterstained nuclei using Adobe Photoshop software (Adobe System Inc., San Jose, CA).

\subsection{In situ hybridization}

After the partial salmon OMP1 cDNA (389 bp; homology vs. salmon OMP2 is 94.3\%) was linearized, digoxigenin (DIG)-labeled antisense and sense cRNA probes were prepared with T7 and SP6 RNA polymerase using a DIG RNA Labeling Kit (Boehringer Mannheim, Mannheim, Germany) according to the manufacturer's instructions. Sections adjacent to those used for the above immunohistochemistry were digested with $5 \mu \mathrm{g} / \mathrm{mL}$ proteinase $\mathrm{K}$ in $10 \mathrm{mmol} / \mathrm{L}$ Tris-HCl, $1 \mathrm{mmol} / \mathrm{L}$ EDTA (pH 8.0) for $20 \mathrm{~min}$ at $37^{\circ} \mathrm{C}$, and treated with 0.2 $\mathrm{mol} / \mathrm{L} \mathrm{HCl}$ for $10 \mathrm{~min}$ and $0.25 \%$ acetic anhydrate in $0.1 \mathrm{~mol} / \mathrm{L}$ triethanolamine- $\mathrm{HCl}(\mathrm{pH} 8.0)$ for 10 min. Hybridization and immunohistochemical detection for hybridized signals were performed using the method of Kudo et al. (1999). In control experiments, the sense RNA probe was hybridized to tissue sections as described for the antisense RNA probe.

Alternatively, the sections were treated with $20 \mu \mathrm{g} / \mathrm{mL}$ RNase A for $30 \mathrm{~min}$ at $37^{\circ} \mathrm{C}$ prior to in situ hybridization.

\section{Results}

\subsection{Nucleotide sequence of salmon OMP cDNA}


The degenerate RT-PCR generated an amplicon of expected size (155 bp) from the olfactory epithelium. This amplicon was sequenced, and the nucleotide sequence was that of OMP. 3'-RACE reactions using the sense primer OMP1sp-3 in combination with the adapter amplified the entire 3' terminus of cDNA (including the poly-A tail). On the other hand, 5'RACE reactions using the antisense primer OMP1sp-5 or OMP2sp-5 were conducted to amplify the remainder of the 5 ' end, a portion of the untranslated region. Two salmon OMP1 and -2 cDNAs contained 1818 and 1750 nucleotides with a putative 519-bp open reading frame (ORF) and polyadenylation signal, AATAAA, located 23 and 17 bp upstream of the poly (A) ${ }^{+}$tail, respectively (Fig. 1). These cDNAs contained a coding region encoding 173 amino acid residues, and the molecular mass of the protein was calculated to be 19,581.17 and 19,387.11Da, respectively.

\subsection{Sequence comparisons}

Alignment of the deduced amino acid sequences is shown in Figure 2. They showed a 90.17\% (sockeye salmon2), 62.99\% (zebrafish1: GenBank accession no. AB073551), $64.52 \%$ (fugu, Takifugu rubripes: Ensembl Translation ID. SINFRUP00000150379), 52.53\% (Xenopus: XLA010978), 50.62\% (human: GenBank accession no. HSU01212), and 51.23\% (rat and mouse: $\underline{\text { RNM26926 }}$ and MMU01213 , respectively) similarity at the amino acid level with the present sequencing. Medaka (Oryzias latipes) and Japanese loach (Misgurnus anguillicaudatus) OMPs underwent partial sequencing (Yasuoka et al., 1999 and IrieKushiyama et al., 2004, respectively). The present sequence of salmon and other vertebrate OMPs demonstrated a marked conservation of the two domains (Fig. 2). These regions, ranging from positions 92 to 110 and from 130 to 152, were highly conserved and demonstrated a higher sequence identity of 84 and 78\% within sOMP and other OMPs. Phylogenic analysis of the full-length salmon OMP1 and -2 in comparison with other reported OMPs indicated that the salmon OMPs could be clearly segregated into the teleost OMP branch (Fig. 3).

\subsection{Expression of OMP in olfactory tissues}

Soluble extracts from lacustrine sockeye salmon olfactory rosettes and rat nasal cavities were resolved by SDS-PAGE (lanes 2 and 3 in Fig. 4). On western blot analysis, a new polyclonal antibody to OMP produced in this study recognized a band with a molecular mass of 20 and $19 \mathrm{kDa}$ in the salmon olfactory rosettes and rat nasal cavities, respectively (lanes 4 
and 5 in Fig. 4). Control immunoreaction using pre-immuno serum showed no detectable positive immunoreactivities in all cases.

Analysis of serial sections of the lacustrine sockeye salmon olfactory epithelium showed immunoreactivities for OMP in the perinuclear region, dendric cytosol, and axons of the ORNs (Fig. 5A), and signals for OMP mRNA using labeled cRNA antisense probes in the perinuclear regions of these ORNs (Fig. 5B). Hybridization with the labeled sense control probe identified no detectable hybridized signals in adjacent sections. In addition, immunoreactivities for OMP were also found in the perinuclear region, dendric cytosol, and axons of rat ORNs (Fig. 5D).

No clear differences in the localization and the signal intensity for OMP were observed between males and females in both immunohistochemistry and in situ hybridization examinations.

\subsection{Comparisons of immunoreactivites for OMP and other maker molecules}

Analysis of serial sections of the lacustrine sockeye salmon olfactory epithelium showed immunoreactivities for OMP, soGST, and PGP9.5 in the ORNs (Fig. 6). The number of ORNs positive for OMP was markedly less than those for other molecules. Furthermore, some ORNs near the basal region in the olfactory epithelia showed immunoreactivities for PGP9.5 (Fig. 6C). No distinct immunohistochemical differences for these three molecules in ORNs between males and females were detected.

Double immunofluorescence labeling of OMP and soGST in the same section of a single specimen of olfactory epithelium from lacustrine sockeye salmon showed immunoreactivities in a certain population of ORNs for either soGST (red signals) or the colocalization (yellow or yellow green signals) of both molecules (Fig. 7D). ORNs that were independently immunoreactive to OMP (green signals) were not detected in this section. Before immunoreaction for soGST, fluorescence signals were abolished in all cases. Even when the order of the primary antibody was changed, the same result was obtained.

\section{Discussion}

The present study isolated two subtypes of cDNA clone for a salmon OMP gene expressed in the olfactory epithelium of lacustrine sockeye salmon. These OMPs, which show high-level homology, may reflect ancestral tetraploidy in salmonid fish (Johnson et al., 1987).

Regarding this, some genes encoding salmon-expressed protein have sequences of two 
subtypes (e.g., Ono et al., 1988; Harada et al., 2008). Sequence comparison demonstrated a moderate overall homology with highly conserved OMPs from other vertebrates; however, two domains emerged that are identical in all OMP subtypes. These two domains were equivalent to the "Eph2B receptor-like loop" and " $\beta-7$ domain", clarified by X-ray crystallography (Smith et al., 2002; Baldisseri et al., 2002). The EphB2 receptor is a tyrosine kinase that is activated by interaction with B-type ephrins, a family of closely related axonal guidance factors (Himanen et al., 1998; Cramer et al., 2006). In invertebrates, several ORN-specific marker proteins have been identified from the olfactory organs (e.g., lobster, Homarus americanus, Hollins et al. 2003; land snail, Eobania vermiculata, Mazzatenta et al. 2004). However, these amino acid and nucleotide sequences indicated that these molecules of the invertebrates were not homologous to vertebrate OMP including salmon OMP. It is likely that OMP functions in only vertebrate ORN, and it is conserved phylogenically in vertebrate. Our in situ hybridization and immunohistochemistry studies demonstrated the gene and protein expression of OMP in ORNs of the lacustrine sockeye salmon using specific probes and antibodies for salmon OMP, respectively. The present immunoreactivities of OMP was similar to that in rainbow trout using antibodies against mammalian OMP (Riddle and Oakley, 1992). In teleosts, two morphological distinct ORN types, ciliated and microvillous ORNs, exist according to the ultrastructure of the olfactory knob in the dendrite of the ORN (Zeiske et al., 1992). Our previous study indicated that the immunoreactivites of soGST exist in the cytoplasm of both ORN types in the lacustrine sockeye salmon by post-embedding immunoelectron microscopy (immuno-gold method; Kudo et al., 1996). The ultrastructure of the olfactory knob in the dendrite of the microvillous ORN (Yamamoto and Ueda, 1977) is very similar to that of the mammalian vomeronasal neurons (Takami et al., 2005), although functional information on the microvillous ORN is scarce in salmon (Sato and Suzuki, 2001). At the same time, the mammalian vomeronasal neurons indicated the expression of OMP (Johnson et al., 1993; Takami et al., 1993). However, OMP of zebrafish was expressed only in the ciliated ORNs, and not in the microvillous ORNs (Sato et al., 2005). Therefore, it is suitable to consider that OMP is expressed in ciliated ORN type in salmon.

The comparison among OMP, GST, and PGP9.5 in salmon olfactory epithelium demonstrated that PGP9.5-immunoreactive ORNs were the largest in number, and OMPimmunoreactive ORNs were the least common. Furthermore, double immunofluorescence labeling of OMP and GST revealed that ORNs in the olfactory epithelia could be divided into 
two groups based on their distinct immunoreactivities: i) ORNs immunoreactive for both OMP and GST; and ii) ORNs immunoreactive for only GST. In mammals, OMP is abundantly expressed in mature ORNs (Farbman and Margolis, 1980), and PGP9.5 is expressed in ORNs of broad developmental stages, including immature ORNs (Taniguchi et al., 1993). In teleosts, Nile tilapia (Oreochromis niloticus) ORNs expressed an ubiquitin C-terminal hydrolase (EC 3.4.19.12) homologous to PGP9.5 (Mochida et al., 2002). An immunohistochemical study of GST during ontogeny indicated that GST started to be synthesized in embryonic ORNs of lacustrine sockeye salmon after the projection of olfactory nerve axons to the olfactory bulb (Yanagi et al., 2004). These findings strongly suggest that salmon OMP is expressed as well as mammalian OMP in mature ORNs, and GST is expressed following the appearance of PGP9.5 in semi-mature ORNs.

Several ORN-related proteins except for OMP and GST have been identified and applied as molecular markers to study olfactory function, including olfactory receptors (ORs: Morinishi et al., 2007), and calretinin (calcium-binding protein: Castro et al., 2008) in the olfactory system of several other salmonid fish. However, a single ORN expresses only one allele of a given OR gene (Chess et al., 1994) although the regulation of OR gene expression is unclear in the salmon ORN at present. It is difficult to discuss the condition of all ORNs based on the analyses of only a few ORs. Calretinin is promising as an ORN marker molecule in salmonid olfactory epithelia although biochemical and molecular biological information is insufficient in salmon ORNs. However, calretinin is widely distributed in various other neurons and chemosensory cells of the teleosts (Levanti et al. 2008). It seems reasonable to suppose that our salmon OMP is the most suitable as an ORN specific detectable marker because its gene expression has been proven in salmon olfactory epithelium.

In conclusion, we performed molecular cloning and verified the expression of salmon OMP in salmon olfactory epithelium. Salmon OMP has been confirmed to be a useful molecular marker for the detection of ORNs in the salmon olfactory system. 


\section{Acknowledgements}

This study was supported in part by Grant-in-Aids for Scientific Research (C) from the Japan Society for the Promotion of Science (JSPS; No. 2058018808), and for Young Scientists (B) from the Ministry of Education, Culture, Sports, Science and Technology, Japan (MEXT; No. 17710049).

\section{References}

Baker, H., Grillo, M., Margolis, F.L., 1989. Biochemical and immunocytochemical characterization of olfactory marker protein in the rodent central nervous system. J. Comp. Neurol. 285, 246261.

Baldisseri, D.M., Margolis, J.W., Weber, D.J., Koo, J.H., Margolis, F.L., 2002. Olfactory marker protein (OMP) exhibits a $\beta$-clam fold in solution: Implications for target peptide interaction and olfactory signal transduction. J. Mol. Biol. 319, 823-837.

Buiakova, O.I., Baker, H., Scott, J.W., Farbman, A.I., Kream, R., Grillo, M., Franzen, L., Richman, M., Davis, L.M., Abbondanzo, S., Stewart, C.L., Margolis, F.L., 1996. Olfactory marker protein (OMP) gene deletion causes altered physiological activity of olfactory sensory neurons. Proc. Natl. Acad. Sci. USA. 93, 9858-9863.

Castro, A., Becerra, M., Anadón, R., Manso, M.J., 2008. Distribution of calretinin during development of the olfactory system in the brown trout, Salmo trutta fario: Comparison with other immunohistochemical markers. J. Chem. Neuroanat. 35, 306-316.

Celik, A., Fuss, S.H., Korsching, S., 2002. Selective targeting of zebrafish olfactory receptor neurons by the endogenous OMP promoter. Eur. J. Neurosci. 15, 798-806.

Chess, A., Simon, I., Cedar, H., Axel, R., 1994. Allelic inactivation regulates olfactory receptor gene expression. Cell, 78, 823-834.

Chomczynski, P., Sacchi, N., 1987. Single-step method of RNA isolation by acid guanidinium thiocyanate-phenol-chloroform extraction. Anal. Biochem. 162, 156-159.

Cramer, K.S., Cerretti, D.P., Siddiqui, S.A., 2006. EphB2 regulates axonal growth at the midline in the developing auditory brainstem. Dev. Biol. 295, 76-89.

Farbman, A.I., Margolis, F.L., 1980. Olfactory marker protein during ontogeny: immunohistochemical localization. Dev. Biol. 74, 205-215.

Ferrando, A., Bottaro, M., Gallus, L., Girosi, L., Vacchi, M., Tagliafierro, G., 2007. First detection of olfactory marker protein (OMP) immunoreactivity in the olfactory epithelium of a cartilaginous fish. Neurosci. Lett. 413, 173-176.

Harada, M., Yoshinaga, T., Ojima, D., Iwata, M., 2008. cDNA cloning and expression analysis of thyroid hormone receptor in the coho salmon Oncorhynchus kisutch during smoltification. Gen. Comp. Endocrinol. 155, 658-667. 
Himanen, J.P., Henkemeyer, M., Nikolov, D.B., 1998. Crystal structure of the ligand-binding domain of the receptor tyeosine kinase EphB2. Nature 396, 486-491.

Hollins, B., Hardin, D., Gimelbrant, A.A., McClintock, T.S., 2003. Olfactory-enriched transcripts are cell-specific marker in the lobster olfactory organ. J. Comp. Neurol. 455, 125-138.

Irie-Kushiyama, S., Asano-Miyoshi, M., Suda, T., Abe, K., Emori, Y., 2004. Identification of 24 genes and two pseudogenes coding for olfactory receptors in Japanese loach, classified into four subfamilies: a putative evolutionary process for fish olfactory receptor genes by comprehensive phylogenetic analysis. Gene 325, 123-135.

Ivic, L., Pyrski, M.M., Margolis, J.W., Richards, L.J., Firestein, S., Margolis, F.L., 2000.

Adenoviral vector-mediated rescue of the OMP-null phenotype in vivo. Nat. Neurosci. 3, 1113-1120.

Johnson, E.W., Eller, P.M., Jafek, B.W., 1993. An immuno-electron microscopic comparison of olfactory marker protein localization in the supranuclear regions of the rat olfactory epithelium and vomeronasal organ neuroepithelium. Acta Oto-laryngol. 113, 766-771.

Johnson, K.R., Wright, J.E., May, B., 1987. Linkage relationships reflecting ancestral tetraploidy in salmonid fish. Genetics 116, 579-591.

Keller, A., Margolis, F.L., 1975. Immunological studies of the rat olfactory marker protein. J. Neurochem. 24, 1101-1106.

Kudo, H., Ueda, H., Yamauchi, K., 1996. Immunocytochemical investigation of a salmonid olfactory system-specific protein in the kokanee salmon (Oncorhynchus nerka). Zool. Sci. 13. 647-653.

Kudo, H., Ueda, H., Mochida, K., Adachi, S., Hara, A., Nagasawa, H., Doi, Y., Fujimoto, S., Yamauchi, K., 1999. Salmonid olfactory system-specific protein (N24) exhibits glutathione Stransferase class pi-like structure. J. Neurochem. 72, 1344-1352.

Kudo, H., Doi, Y., Nishino, T., Nara, S., Hamasaki, K., Fujimoto, S., 2000. Dietary zinc deficiency decreases glutathione $S$-transferase expression in the rat olfactory epithelium. J. Nutr. 130, 3844.

Levanti, M.B., Montalbano, G., Laurà, R., Ciriaco, E., Cobo, T., Garcia-Suarez, O., Germanà, A., Vega, J.A., 2008. Calretinin in the peripheral nervous system of the adult zebrafish. L. Anat. 212, 67-71.

Lowry, O.H., Rosebrough, N.J., Farr, A.L., Randall, R.J., 1951. Protein measurement with the folin phenol reagent. J. Bio.1 Chem. 193, 265-275.

Mazzatenta, A., Pelosi, P., Cellerino, A., 2007. Cloning of an olfactory sensory neuron-specific protein in the land snail (Eobania vermiculata). Proc. R. Soc. Lond. B 271 (Suppl.), S46-S49.

Mochida, K., Matsubara, T., Kudo, H., Andoh, T., Ueda, H., Adachi, S., Yamauchi, K., 2002.

Molecular cloning and immunohistochemical localization of ubiquitin C-terminal hydrolase 
expressed in testis of a teleost, the Nile Tilapia, Oreochromis niloticus. J. Exp. Zool. 293, 368383.

Morinishi, F., Shiga, T., Sizuki, N., Ueda, H., 2007. Cloning and characterization of an odorant receptor in five Pacific salmon. Comp. Biochem. Physiol. B Biochem. Mol. Biol. 148, 329336.

Nishino, T., Kudo, H., Doi, Y., Maeda, M., Hamasaki, K., Morita, M., Fujimoto, S., 2001. Immunocytochemistry of glutathione $S$-transferase in taste bud cells of rat circumvallate and foliate papillae. Chem. Senses 26, 179-188.

Ono, M., Wada, C., Oikawa. I., Kawazoe, I., Kawauchi, H., 1988. Structures of two kinds of mRNA encoding the chum salmon melanin-concentrating hormone. Gene 71, 433-438.

Riddle, D.R., Oakley, B., 1992. Immunocytochemical identification of primary olfactory afferents in rainbow trout. J. Comp. Neurol. 324, 575-589.

Saitoh, N., Nei, M., 1987. The neighbor-joining method: new method for reconstructing phylogenic tree. Mol. Biol. Evol. 4, 406-425.

Sato, K., Suzuki, N., 2001. Whole-cell response characteristics of ciliated and microvillous olfactory receptor neurons to amino acids, pheromone candidates and urine in rainbow trout. Chem. Senses 26, 1145-1156.

Sato, Y., Miyasaka, N., Toshihara, Y., 2005. Mutually exclusive glomerular innervation by two distinct types of olfactory sensory neurons revealed in transgenic zebrafish. J. Neurosci. 25, 4889-4897.

Shimizu, M., Kudo, H., Ueda, H., Hara, A., Shimazaki, K., Yamauchi, K., 1993. Identification and immunological properties of an olfactory system-specific protein in kokanee salmon (Oncorhynchus nerka). Z Zool. Sci. 10, 287-294.

Smith, P.C., Firestein, S., Hunt, J.F., 2002. The crystal structure of the olfactory marker protein at 2.3 Å resolution. J. Mol. Biol. 319, 807-821.

Stabell, O.B., 1992. Olfactory control of homing behaviour in salmonids. In: Hara, T.J. (Ed), Fish Chemoreception, Chapman and Hall, London, pp. 249-270.

Starcevic, S.L., Zielinski, B.S., 1995. Immunohistochemical localization of glutathione S-transferase pi in rainbow trout olfactory receptor neurons. Neurosci. Lett. 183, 175-178.

Starcevic, S.L., Zielinski, B.S., 1997. Glutathione and glutathione S-transferase in the rainbow trout olfactory mucosa during retrograde degeneration and regeneration of the olfactory nerve. Exp. Neurol. 146, 331-340.

Takami, S., Getchell, M.L., Chen, Y., Monti-Bloch, L., Berliner, D.L., Stensaas, L,J,, Getchell, T.V., 1993. Vomeronasal epithelial cells of the adult human express neuron-specific molecules. Neuroreport 4, 375-378. 
Takami, S., Iwai, T., Hasegawa, R., Nishiyama, F., 2005. Ultrastructural localization of alphagalactose-containing glycoconjugates in the rat vomeronasal organ. J. Neurocytol. 34, 123133.

Taniguchi, K., Saito, H., Okamura, M., Ogawa, K., 1993. Immunohistochemical demonstration of protein gene product 9.5 (PGP9.5) in the primary olfactory system of the rat. Neurosci. Lett. 156, 6-24.

Tierney, K.B., Sampson, J.L., Ross, P.S., Sekela, M.A., Kennedy, C.J., 2008. Salmon olfaction is impaired by an environmentally realistic pesticide mixture. Environ. Sci. Technol. 42, 49965001.

Yamamoto, M., Ueda, K., 1977. Complative morphology of fish olfactory epithelium Salmoniforms. Bull. Jpn. Soc. Sci. Fish. 43, 1163-1174.

Yanagi, S., Kudo, H., Doi, Y., Yamauchi, K., Ueda, H., 2004. Immunohistochemical demonstration of salmon olfactory glutathione $S$-transferase class pi (N24) in the olfactory system of lacustrine sockeye salmon during ontogenesis and cell proliferation. Anat. Embryol. 208, 231-238.

Yasuoka, A., Endo, K., Asano-Miyoshi, M., Abe, K., Emori, Y., 1999. Two subfamilies of olfactory receptor genes in medaka fish, Oryzias latipes: Genomic organization and differential expression in olfactory epithelium. J. Biochem. 126, 866-873.

Yoshida, T., Ito, A., Matsuda, N., Mishina, M., 2002. Regulation by protein kinase A switching of axonal pathfinding of zebrafish olfactory sensory neurons through the olfactory placodeolfactory bulb boundary. J. Neurosci. 22, 4964-4972.

Youngentob, S.L., Margolis, F.L., 1999. OMP gene deletion causes an elevation in behavioral threshold sensitivity. Neuroreport 10, 15-19.

Youngentob, S.L., Margolis, F.L., Youngentob, L.M., 2001. OMP gene deletion results in an alteration in odorant quality perception. Behav. Neurosci. 115, 626-631.

Zeiske, E., Theisen, B., Breuker, H., 1992. Structure, development and evolutionary aspects of the pheripheral olfactory system. In: Hara, T.J. (Ed), Fish Chemoreception, Chapman and Hall, London, pp. 13-39. 
Table 1. Primer Sets Used for RT-PCR, and 5'- and 3'-RACE for Sequence Analyses of Lacustrine Sockeye Salmon, Oncorhynchus nerka, OMP1 and -2.

\begin{tabular}{lcc}
\hline Primer name & Sequence & Nucleotide position in OMP1 \\
\hline OMPdn-F & 5'-TTNATGACNCGNCAGCT-3' & $391-407$ \\
OMPdn-R & 5'-AGRAARTACATVACYTTKC-3' & $527-545$ \\
& & \\
OMP1sp-5 & 5'-GTACATGACCTTGCGGACCTTGGCCAGCTC-3' & $511-540$ \\
OMP1sp-3 & 5'-GATGACCCGGCAGCTTCTAGAACCCGTCGG-3' & 393-422 \\
OMP2sp-5 & 5'-GTTACCCATAGACTTCCAGTCATTGCCCGA-3' & $814-843^{\mathrm{a}}$ \\
\hline
\end{tabular}

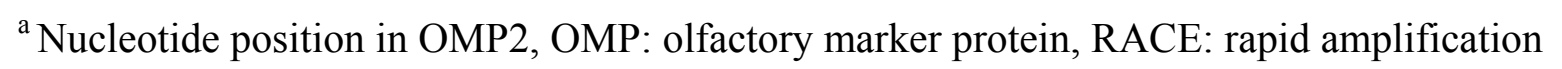
of cDNA ends. 


\section{Captions to figures}

Fig. 1. Nucleotide and deduced amino acid sequences of the lacustrine sockeye salmon, Oncorhynchus nerka, cDNA of OMPs. The putative polyadenylation signal is in bold. The positions of degenerate PCR primers are underlined.

Fig. 2. Alignments of amino acid sequences of the OMPs of the lacustrine sockeye salmon, Oncorhynchus nerka, and those of other vertebrates (Zebrafi, Danio rerio; Fugu, Takifugu rubripes; Medaka, Oryzias latipes; Loach, Misgurnus anguillicaudatus; Xenopus, Xenopus laevis; Human, Homo sapiens; Rat, Rattus norvegicus; Mouse, Mus musculus). Sequences are positioned to yield maximum homology. Amino acids identical between salmon OMP1 and other OMPs are shown by dashes (-). The synthesized peptide sequence for the antigen of salmon OMP antibody is shaded in the salmon OMP1 (92-110). The region of Eph2B receptor-like loop is boxed (94-110).

Fig. 3. Evolutionary relationships between the known OMPs. The phylogenic tree was constructed using the neighbor-joining method. Comparisons were made with amino acid sequences of salmon, Oncorhynchus nerka, 1 (GenBank accession no. $\underline{\mathbf{A B 4 9 0 2 5 0}}$ ) and 2 (吕490251) , zebrafish, Danio rerio, 1 (GenBank accession no. $\underline{\mathbf{A B 0 7 3 5 5 1}}$ ) and 2 (F457189), fugu (Takifugu rubripes, Ensembl Translation ID. SINFRUP00000150379),

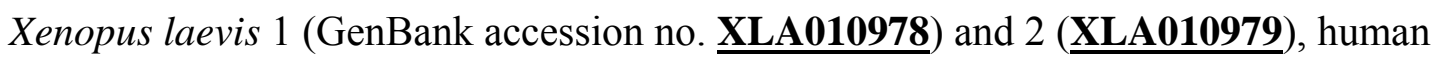

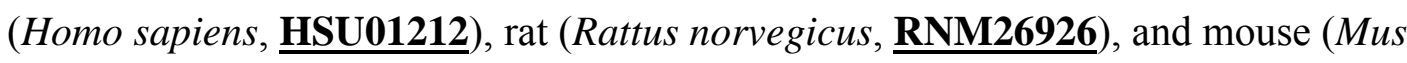

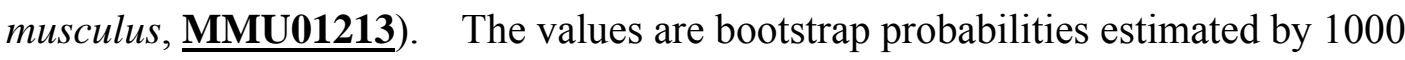
replications. The horizontal line indicates the genetic distance.

Fig. 4. SDS-PAGE (1-3) and western blotting (4 and 5) of soluble extracts in lacustrine sockeye salmon, Oncorhynchus nerka, olfactory rosettes (2 and 4), and rat, Rattus norvegicus, nasal cavities (3 and 5). Anti-salmon OMP antibody (1:500) recognizes a band with a molecular weight of $20 \mathrm{kDa}$ (upper arrow) in the salmon olfactory rosettes, and $19 \mathrm{kDa}$ (lower arrow) in the rat nasal cavities. Positions of low-molecular-weight markers (1), expressed in $\mathrm{kDa}$, are indicated on the left side of the figure. 
Fig. 5. Immunohistochemical localization of OMP in the olfactory epithelium of lacustrine sockeye salmon, Oncorhynchus nerka (A). Adjacent sections show expressions of OMP mRNA demonstrated by in situ hybridization (B) and Delafield's hematoxylin and eosin staining (C). Immunohistochemical localization of OMP using anti-salmon OMP antibody in rat, Rattus norvegicus, olfactory epithelium (D). Bars: $20 \mu \mathrm{m}$.

Fig. 6. Serial sections of the olfactory epithelium of lacustrine sockeye salmon,

Oncorhynchus nerka. Immunoreactivities for OMP (A), salmon olfactory glutathione $S$ transferase pi (soGST; B), and protein gene product 9.5 (PGP9.5; C). Delafield's hematoxylin and eosin staining (D). Bar: $50 \mu \mathrm{m}$.

Fig. 7. Double immunofluorescence labeling of soGST (red signal; A) and OMP (green signal; B) in the olfactory epithelium of lacustrine sockeye salmon, Oncorhynchus nerka. Blue signals indicate nuclei by DAPI staining (C). Combined double-labeled image of OMP and soGST shown in (B) and (A). The yellow or yellow green signal reflects overlapping of immunoreactivities for OMP and soGST (D). Bar: $50 \mu \mathrm{m}$. 


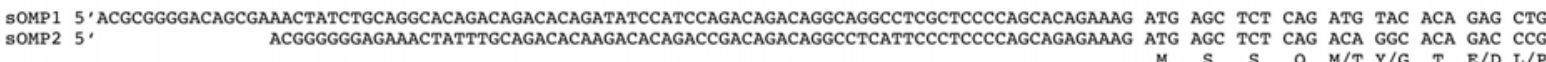
SOMP2 5 ,

TCT GCG GCT CCC TCG TCT GGC TCA GCC CTG GAG CTA CGC TTT GCA GAG GAC ACC TCT CTC ACT GAG GTG ATG CGG CTA CGT GTC CAG TCC CTG CAG CGG

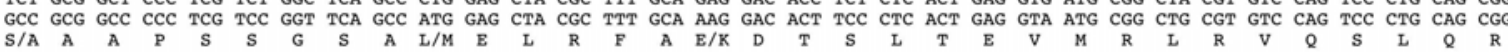
AGC GGT CAG AGG CGA CAG GAG GGG GAG CGG TTG CTC CTC CCC CAC GAG GCT GTC TAC CGT CTG GAC TTT GCC AAT CAG GAG CTG ACG TTC GTC CAC TGC

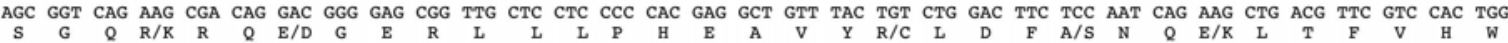
TCG GTG TCT CTG ATT GGC AAT GGC AGA GTG ACC GTC ACG GGG ATC TCC CAG CTC TGG ACC CCT GAC CTC ACA CAC TTG ATG ACC CGG CAG CTT CTA GAA TCG GTG TCT CTG ATT GGT CAT GGC AGA GTG ACC ATC ACA GGG ATC TCC CAG CTC TGG ACC CCT GAC CTC ACA CAC CTG ATG ACC CGG CAG CTT CTT GA

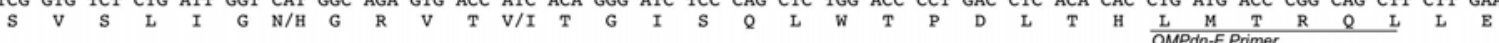
CCC GTC GGA ACA TTC TGG CGG AAC GCT GGC GAC CCG GAG GAC ACA CCC CTC AAG TGT CTG GAG GCA GAC ATC CAG GAG TTT GGG GAG CGA ATC GCG GAC

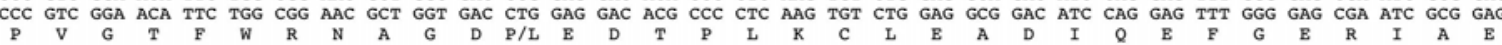
CTG GCC AAG GTC CGC AAG GTC ATG TAC TTC CTG TTT GCC TTT AAG GAG GGG GCA GAG GCT GAC AAG GTC AGC ATC TCC GTG GAG TTT AAT CAG GCC TGA

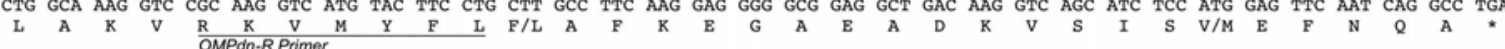

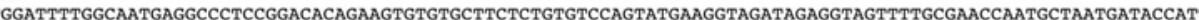
CCTACAAACCTTAAAGGGATGCTTCTGGATTTTGGCAATGAGGCCCTCTGGATACCAAAGTGTGTACTTTTCTGTGTCCAGTGTGAAGAGGGATGGAGGTGGTTTTGCGAGCCAATGCTAACTAGCTTTCG

ATGATACCAACACTAGTTAGCATTGGCTCACAAAACTATGTGAAACTACATCTAACTTCCTTCATACTGGACATAAACATACAAATGGTATCCACGAGTTCATCTGACTCTGGGGAAGTAGATAAAGGGCC

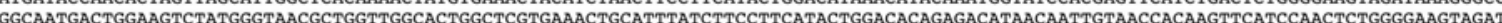
TCATTGACAAAATCCCGAAGTATCCCTTTAACTGCTTCCTCTTCCCTCTACTCT AAAGGACCTCATTCC CCCACACAAACCCACGAGTCCCATCTCTCATCTGAGTGTGTGCGCACTTCCTTCCTGAACATCTATCTATCTATGCATGTCAGTCAATAATCTGCTAGAAACCACCTTCTGGAGGTACAGTAGTTACACA ACTCCTATCCTCCTTACGCCCCCCGCCCACACACACTGAGTCCCATCTCTCATCTGTGTGTGCGTGTGTGTGTACTTCCTTCCTGAGTGTCTATCTAGCTATCTATCTATGCATGTCAGTCAACAAGCG TAGTAACAGTAGGCTGCAGAATCACTAACTTAGGTTAGAATCCTATAGCTACGGGTACCTGCCAAAATAAAGGAAACACCAACATAAAGTGTCTTAATAGGGTGTTGGGCCGCCACGAGCCAGAACAGCTT CTAGAAACCATGTTTTGAAGGTAAAGTAGTTACACAGTAGGCTGCAGATTCAAACTATAGATACAGGTAACTGCCAAAATAAAAGGAAACACCAACATAAAGTGTCTTAATAGGGCGTCACCACGAGCCGCC CAGTGCAACTTGACATAGATTCTACAAGTGTCTGGAACTCTATTGGAGGTTTGCGGCACCATTCTTCCAGAAGAAATTCCATAATTTTGGTGTTTTGTTGATGGTGGTGGAAAACGCTGTCTCCTCCGCTCC AGAACAGCTTCAATGCGCCTTGACATAGATTCTCCAAGTGTCTGGTACTATATTGGAGGGATGCAACACCATTCTTCCAAGAGAAATTCCAAGAGAAGTTTTGTTGATGGTGGTGGAAAACGCTGTCTCAG AGAATTTATATATTTAAGTATGACGGGATGTTAACTGCTTAATTAACTCAGGAACCATACCTATGTGGAAGCAGCTGCTTTCAATATACTTTGTATCCCTCATTTACTCAAGTGTTTCCTTTATTTTGGCA 作 GCTTTATTTAGCTGTACATTTATATTGAAACCCTGAATGATATGAATAGCTTGTTCTGATCCTTCTTTATAGGGTATATTACAGAACAAATGCTGCAATGTAACTTCAACCATATTCACTTTGCATGAAAT TATTACTCTCCTATTACACTGCACTGATATACTAGTTACCATATTCACTTTGCATGAAATATCACAACAATATACTGTAAACTGGCCATGTCCTCTACTGCTGTCCAATAAAGAGATGTAGGTACTCCGA

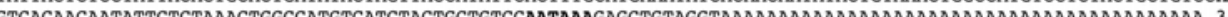

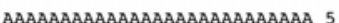

Kudo et al. Fig. 1 


\begin{tabular}{|c|c|c|c|c|c|c|c|}
\hline & & 10 & 20 & 30 & & 50 & \\
\hline Salmon1 & 1 & MSSQMYTELS & AAPSSGSALE & LRFAEDTSLT & EVMRLRVQSL & QRSGQRRQEG & 5 \\
\hline Salmon2 & 1 & $----\mathrm{TG}-\mathrm{DPA}$ & $--------\mathrm{M}-$ & $----\mathrm{K}-----$ & --------- & $-----K--D-$ & \\
\hline Zebraf 1 & 1 & M- & -- & -T-NP-VQ-- & -M-------- & $-Q R--K--D-$ & \\
\hline Eugu & 1 & & $--E \quad-Q$ & -P-RP-NQ-- & ---------- & $-\mathrm{QR}--\mathrm{KK}-\mathrm{D}-$ & \\
\hline Medaka & 1 & & & & & & \\
\hline Loach & 1 & & & & & & \\
\hline Xenopus & 1 & MA & SET-EM & -P-I---Q-- & KC--I---T- & -QKNAKP--- & \\
\hline Human & 1 & MA & EDRPQQPQ-D & MPLVL-QG-- & RQ-----E-- & KQR-EK--D- & \\
\hline Rat & 1 & MA & EDGPQKQQ-D & MPLVL-QD-- & KQ-----E-- & KQR-EKK-D- & \\
\hline Mouse & 1 & MA & EDGPQKQQ-- & MPLVL-QD-- & QQ-----E-- & KQR-EKK-D- & \\
\hline & & 60 & 70 & 80 & 90 & 100 & \\
\hline almon 1 & 51 & ERLLLPHEAV & YRLDFANQE & LTFVHWSVSL & IGNGRVTVTG & ISQLWTPDLT & \\
\hline Salmon2 & 51 & ---------0 & $-\mathrm{C}---\mathrm{S}--\mathrm{K}$ & --------- & $-------I--$ & --------0 & \\
\hline Zebraf 1 & 51 & $----\mathrm{KSN}-\mathrm{H}-$ & $-\mathrm{S}---\mathrm{SE}-\mathrm{A}$ & -H-TC-NICI & SSP--LNIIA & T-ー-ー--ー-- & \\
\hline Fugu & 51 & $----\mathrm{R}-\mathrm{N}---$ & $-----\mathrm{PT}-\mathrm{V}$ & -R-SR-M-R- & ARS--LTI-A & T-ーーー-ー-ー- & \\
\hline Medaka & 51 & & & & & --- & \\
\hline Hoach & 51 & & & & & & \\
\hline Xenopus & 51 & -M--RAN-YI & $--V--S K-K$ & -R-LW-K-H- & KSP-K-MI-- & T--H------ & \\
\hline Human & 51 & $-\mathrm{K}--\mathrm{Q}-\mathrm{A}-\mathrm{S}-$ & $---\mathrm{N}-\mathrm{TQ}-\mathrm{QR}$ & $-\mathrm{Q}-\mathrm{ER}-\mathrm{N}-\mathrm{V}-$ & DKP-K--I-- & $\mathrm{T}--\mathrm{N}------$ & \\
\hline Rat & 51 & $-\mathrm{K}--\hat{\mathrm{R}}-\mathrm{A}-\mathrm{S}-$ & $----I \bar{Q}-\tilde{Q} \mathrm{~K}$ & $-\tilde{\mathrm{Q}}-\mathrm{D}--\mathrm{N}-\mathrm{V}-$ & DKP-K--I-- & $\mathrm{T}--\mathrm{N}------$ & \\
\hline Mouse & 51 & -K-IR-A-S- & $-----\mathrm{IQ}-\tilde{\mathrm{Q}} \mathrm{K}$ & $-\mathrm{Q}-\mathrm{D}--\mathrm{N}-\mathrm{V}-$ & DKP-K--I-- & $\mathrm{T}--\mathrm{N}------$ & \\
\hline & & 110 & 120 & 130 & 140 & 150 & \\
\hline Salmon1 & 101 & HLMTRQLLEP & VGTFWRNAGD & PEDTPLKCLE & ADIQEFGERI & AELAKVRKVM & \\
\hline 2 & 01 & ---------- & ---------- & L-----ー--- & ----ー------ & ---ー-ー---- & \\
\hline Zebraf 1 & 01 & ---------- & T-L---S- - & D-NIQ & $--\mathrm{A}-------$ & ---------- & \\
\hline Fugu & 101 & N-O------- & $\mathrm{A}-\mathrm{S}---\mathrm{GQ}-\mathrm{E}$ & ACG-VVQ-Y- & $--\mathrm{A}-------$ & ------- & \\
\hline Medaka & 101 & $\mathrm{~N}---------$ & I--------E- & $--\mathrm{ES}-\mathrm{L}----$ & $--\mathrm{M}-------$ & $-----I----$ & \\
\hline oach & 101 & ------- & I-Q------- & $---S-I----$ & ---ー-ー-ー-- & $--M--I----$ & \\
\hline Xenopus & 01 & N--------- & SAV-YKKDAN & $D-V E$ & $--\mathrm{A}-------$ & $-----\bar{I}----$ & \\
\hline Human & 101 & N-------D- & TAI---KEDS & DAID & $--\mathrm{AL}-----\mathrm{L}$ & SD---I---- & \\
\hline Rat & 101 & N-------D- & AAI---KEDS & DAMD & $--\mathrm{AL}-----\mathrm{L}$ & SD---I---- & \\
\hline Mouse & 101 & $\mathrm{~N}-------\mathrm{D}-$ & AAI---KEDS & DAMD & $--\mathrm{AL}-----\mathrm{L}$ & SD---I---- & \\
\hline & & 160 & 170 & 180 & 190 & 200 & \\
\hline Salmon 1 & 151 & YFLFAFKEGA & EADKVSISVE & FNQA & & & \\
\hline Salmon2 & 151 & $---\mathrm{L}------$ & $--------\mathrm{M}-$ & ---- & & & \\
\hline Zebraf 1 & 151 & $------E D-L$ & SPES-EC-I- & -QTSK & & & \\
\hline Fugu & 151 & $------E D-C$ & SPETVDSCIT & - & & & \\
\hline Medaka & 151 & -- & & & & & \\
\hline Loach & 151 & - & & & & & \\
\hline Xenopus & 151 & --VIT-LD-- & DPATIEC-IG & $-\mathrm{RA}$ & & & \\
\hline Human & 151 & $---V T-G--V$ & - PANLKA--V & $---\mathrm{L}$ & & & \\
\hline Rat & 151 & $---I T-G--V$ & -PANLKA--V & $---\mathrm{L}$ & & & \\
\hline Mouse & 151 & $---I T-G--V$ & -PANLKA--V & $---L$ & & & \\
\hline
\end{tabular}

Kudo et al.

Fig. 2 


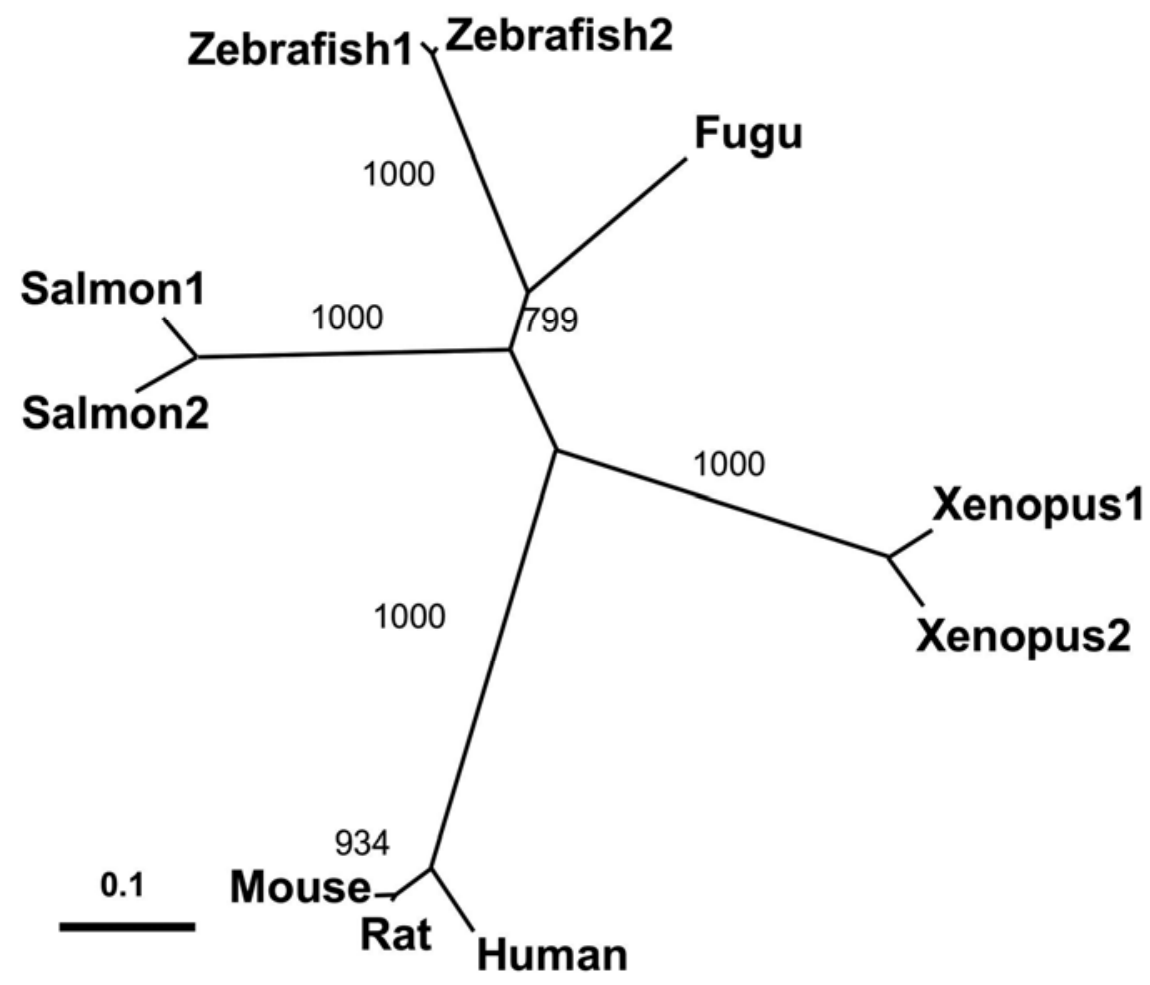

Kudo et al.

Fig. 3 


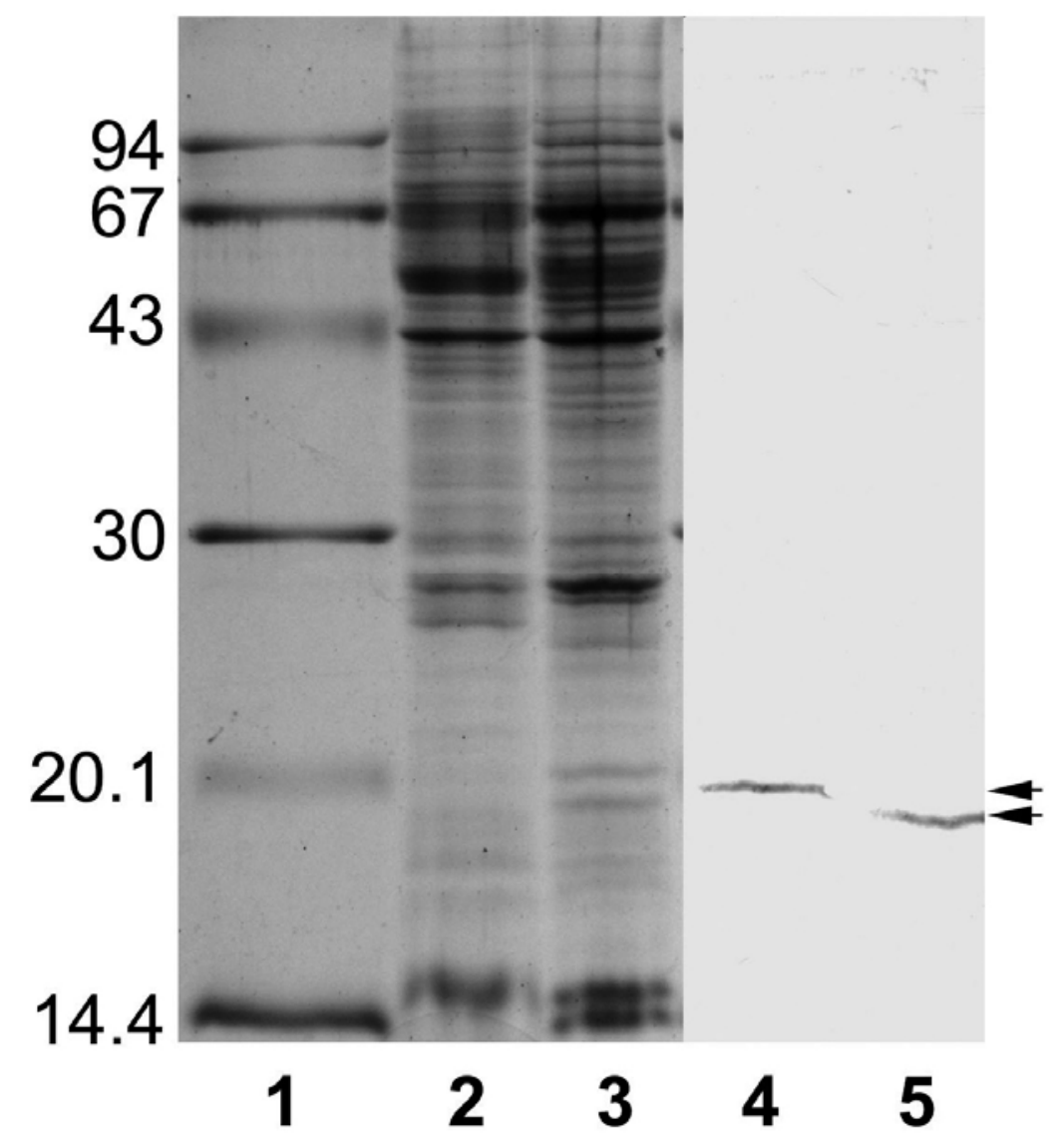

Kudo et al.

Fig. 4 


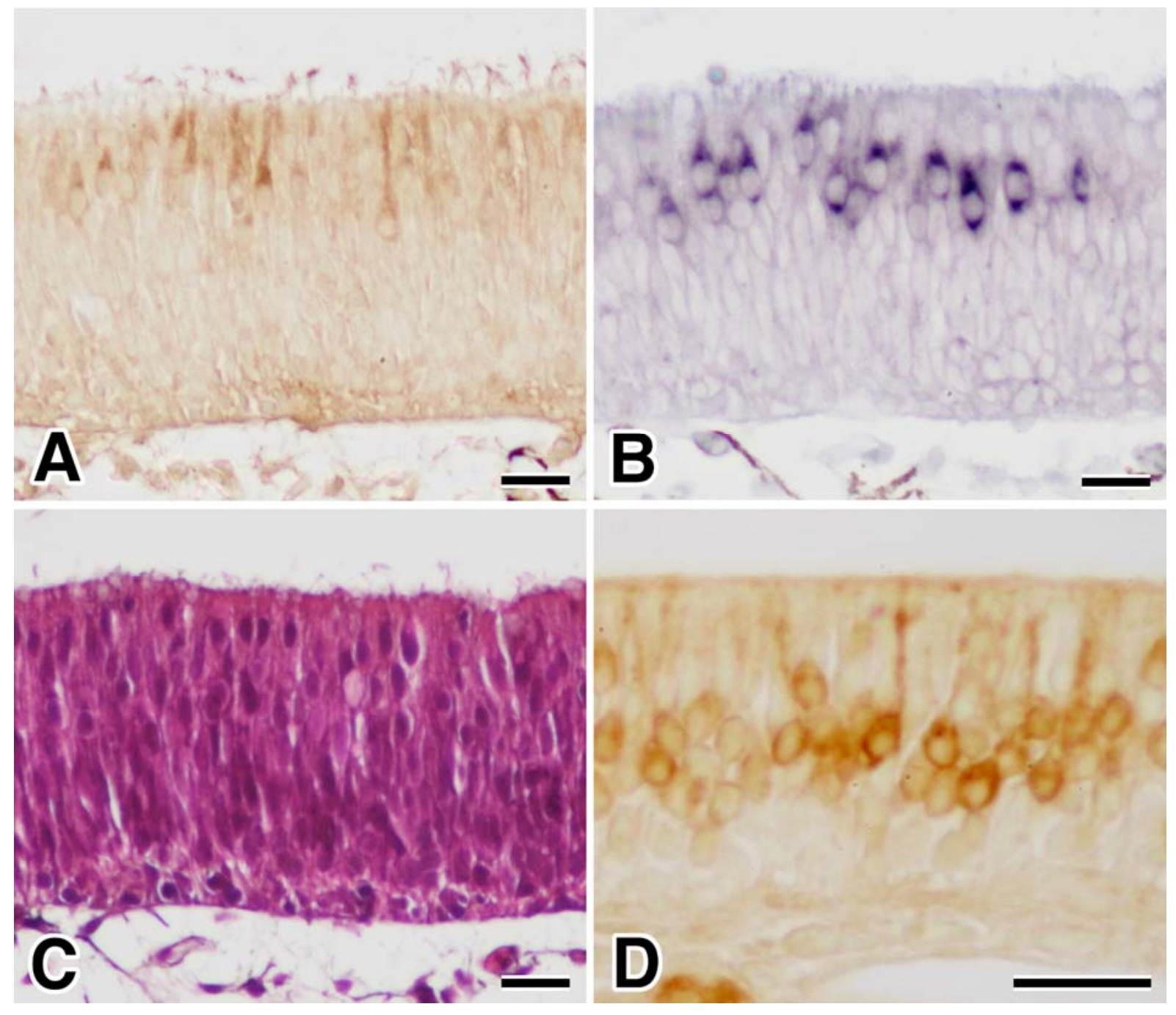

Kudo et al.

Fig. 5 


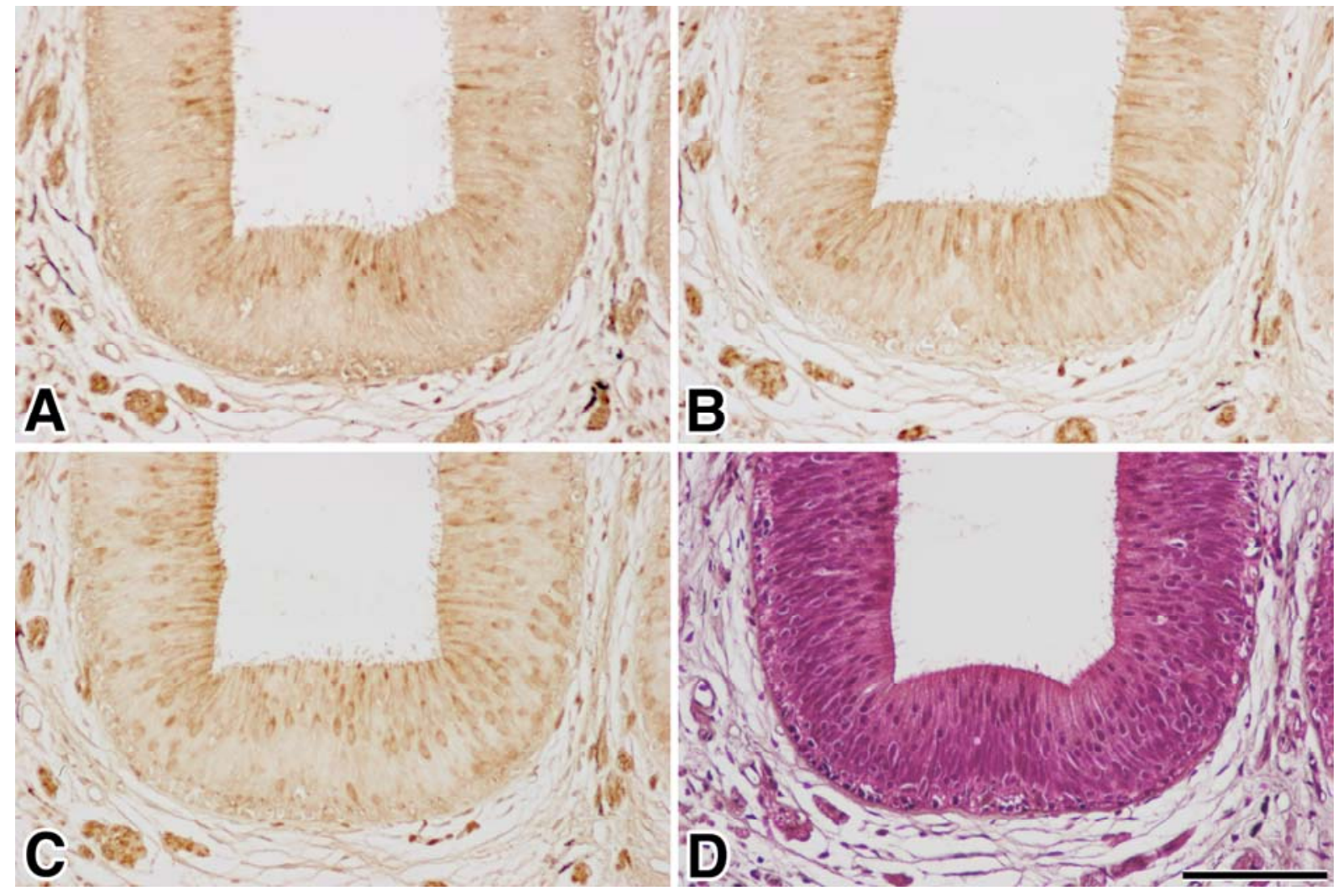

Kudo et al.

Fig. 6 


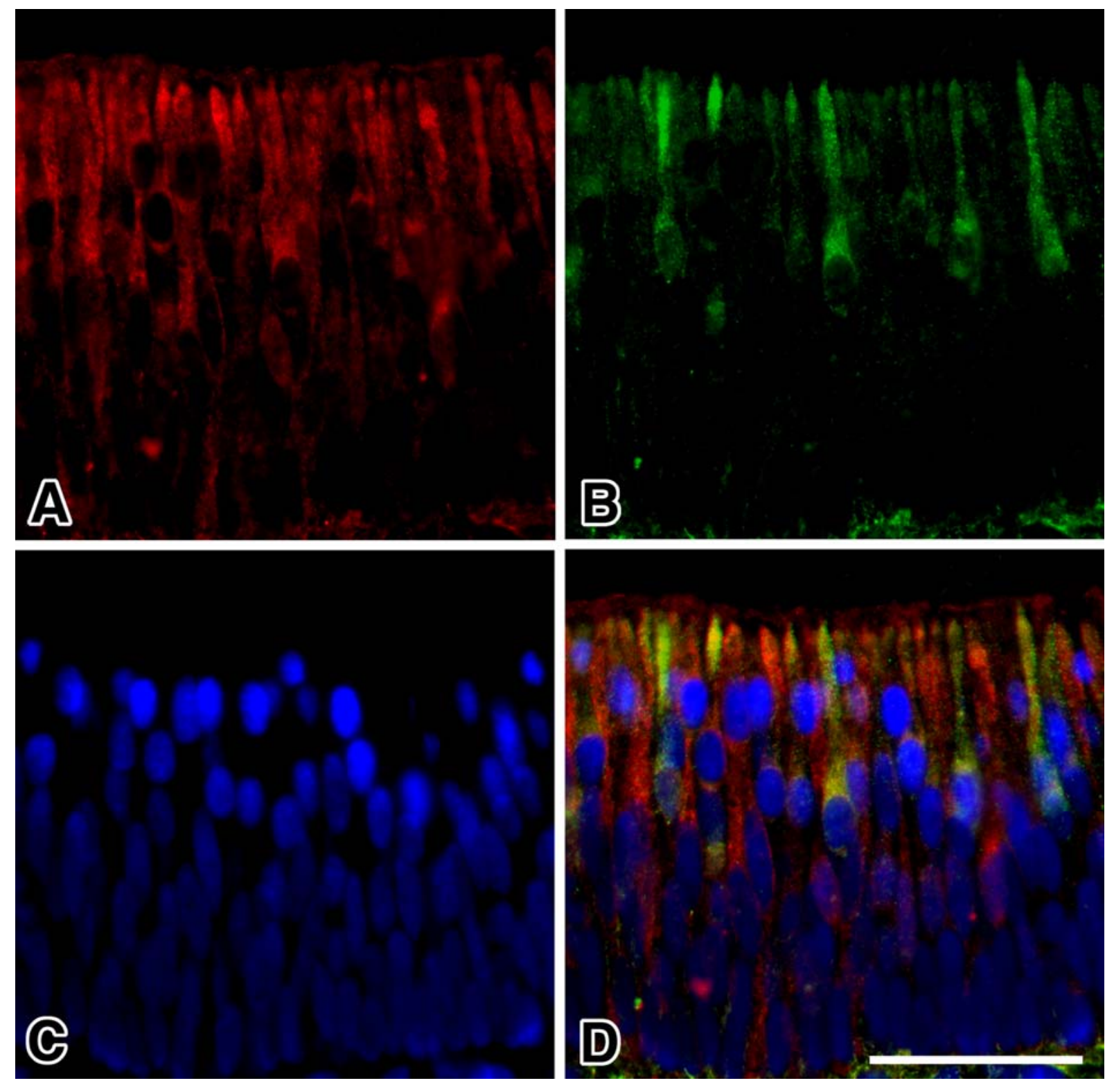

Kudo et al. Fig. 7 